\title{
GaRRIDo Juncal, Andrea, Los Servicios Sociales en el s. XXI. Nuevas tipologías y nuevas formas de prestación
}

\author{
Beatriz Agra Costa \\ Universidad de Santiago de Compostela (España) \\ ORCID: https://orcid.org/0000-0003-1570-9541 \\ beatrizagracosta@gmail.com
}

\begin{abstract}
NOTA BIOGRÁFICA
Graduada en Derecho por la Universidad de Santiago de Compostela, actualmente es Secretaria adjunta del Observatorio Internacional de la Regulación de las Entidades del Sector Público donde desarrolla su actividad investigadora. Sus principales líneas de investigación son: administración electrónica (inteligencia artificial, simplificación y garantía de los derechos de los ciudadanos); contratación administrativa y lucha contra la corrupción, y protección de datos y transparencia.
\end{abstract}

\section{RESUMEN}

Reseña del libro de Andrea GarRIDo Juncal, Los Servicios Sociales en el s. XXI. Nuevas tipologías y nuevas formas de prestación, Aranzadi, Pamplona, 2020, 320 pp. En este libro tras una detallada revisión de la evolución histórica de los servicios sociales y de un minucioso análisis del complejo marco legislativo de estos, consecuencia de nuestro Estado autonómico compuesto, se aborda la delimitación conceptual y la naturaleza jurídica de los antedichos servicios.

\section{PALABRAS CLAVE}

Servicios sociales; evolución histórica; concepto; marco legal; naturaleza jurídica.

\begin{abstract}
Review of the book of Andrea GarRIDo JunCAL, Los Servicios Sociales en el s. XXI. Nuevas tipologías y nuevas formas de prestación, Aranzadi, Pamplona, 2020, 320 pp. This book focuses on a detailed review of the historical evolution of the social services in Spain, an analysis of their complex legislative frame and a determination of their definition and the legal nature of these services.
\end{abstract}

\section{KEYWORDS}

Social servicies; historical evolution; definition; legal frame; legal nature.

En esta interesante monografía, la profesora Andrea Garrido Juncal explica, de forma exhaustiva y precisa, la actual configuración de los servicios sociales en nuestro Ordenamiento. Así, partiendo de una detallada revisión de su evolución histórica y de un minucioso análisis de su marco legislativo, aborda, con claridad y decisión, las trascendentales y complejas cuestiones de su delimitación conceptual y de su naturaleza jurídica.

Hay que destacar que esta es una obra que, por su temática, es previsible que tenga un notable impacto en la comunidad científica y sobre el conjunto de los operadores que trabajan en este sector. Y ello es así porque, en los últimos años, los autores de nuestra disciplina han abandonado el estudio de los servicios sociales, dejando huérfano su examen en un momento crucial, en el que esta labor de análisis es especialmen- 
REALA. Nueva Época - N. ${ }^{\circ} 15$, abril 2021 - ISSN: 1989-8975 - DOI: https://doi.org/10.24965/reala.i15.10884 - [Págs. 111-113]

GARRIDO Juncal, Andrea, Los Servicios Sociales en el s. XXI. Nuevas tipologías y nuevas formas de prestación

Beatriz Agra Costa

te necesaria para garantizar el buen funcionamiento de este sistema. Son imprescindibles trabajos, como el presente, que aporten soluciones claras a los problemas interpretativos, a las antinomias y a las lagunas que se pueden observar en este subsector ordinamental, que proporcionen los instrumentos conceptuales necesarios para mejorar la eficacia, a la hora de conseguir sus fines, de las normas que regulan esta materia y que, finalmente, introduzcan propuestas relevantes de perfeccionamiento de las normas estatales y autonómicas vigentes, a la luz de las soluciones propuestas y de los conceptos forjados.

En esta línea, el objetivo que la autora persigue y que alcanza, sin duda alguna, es llevar a cabo una ordenación y explicación sistemática del panorama legislativo existente en el ámbito de la disciplina de los servicios sociales, tratando de superar los problemas hermenéuticos que esta plantea y proponiendo útiles soluciones dogmáticas para la reconstrucción de las instituciones que están presentes en el campo de los servicios sociales, como forma de intervención de la Administración Pública en la vida de los ciudadanos.

La profundidad y rigor del presente libro se explica, en parte, por el hecho de que el mismo consiste en una prolongación de la investigación doctoral que la autora defendió en el año 2015 en la Universidad de Santiago de Compostela, bajo la dirección del profesor José Luis Carro Fernández-Valmayor, reconocido y prestigioso experto internacional en cuestiones relacionadas con los derechos fundamentales socioeconómicos, del profesor Luis Miguez Macho, autor de la máxima solvencia y con una dilatada lista de publicaciones en campos afines a la temática que se estudia en esta monografía. Actualmente, Andrea Garrido Juncal continúa su carrera investigadora en la citada Universidad, como profesora contratada doctora.

Desde una óptica formal, este libro se organiza en cuatro capítulos. El primero de ellos se dedica a la evolución histórica y situación actual de los servicios sociales. El segundo capítulo tiene por objeto a la compleja cuestión de fijar un concepto inequívoco de servicios sociales y de determinar su escurridiza naturaleza jurídica. El tercer capítulo ofrece un detallado examen del complejo y abundante marco jurídico de los derechos sociales en nuestro Estado autonómico. Y finalmente, el cuarto capítulo se concentra en el estudio del concierto social como forma de gestión de los servicios sociales.

Por lo que respecta al primer capítulo, referente al desarrollo histórico de los servicios sociales, hay que destacar que en él la profesora Garrido Juncal realiza un interesante recorrido por las diferentes fases de la intervención pública dirigidas a satisfacer las necesidades sociales de la población. Así, describe con detalle las características e instituciones propias de los sistemas de beneficencia y asistencia social. Finalmente, en este epígrafe, plantea algunas de las cuestiones más problemáticas que suscitan los servicios sociales en la actualidad, como son: su carácter dinámico y cambiante; la hiperactividad normativa que los rodea y su consideración como servicios públicos de segunda clase, que los hacen susceptibles de sufrir notables regresiones en contextos de crisis económica, como la que se vive hoy en día a causa de la COVID-19.

En el segundo capítulo, la autora, en primer lugar, plantea la complejidad de dar una definición de servicios sociales debido al carácter polisémico de esta expresión, tanto en los textos legislativos, como en la práctica administrativa. Ante esta situación, la profesora Garrido Juncal opta, de modo pragmático, por ofrecer una doble definición, en sentido amplio y en sentido estricto, pero, sobre todo, se decanta por describir el contenido de estos desde una triple perspectiva: desde el punto de vista de los fines, desde el punto de vista de los sujetos (beneficiarios y prestadores) y desde el punto de vista de la naturaleza y caracteres de las prestaciones. Por último, en este segundo capítulo, la profesora Garrido Juncal aborda el debate sobre la naturaleza jurídica de los servicios sociales, en concreto, analiza si pueden y deben ser considerados un servicio público.

En el tercer capítulo, la autora realiza una completa reconstrucción del marco normativo de los servicios sociales en nuestro complejo ordenamiento compuesto autonómico. Así, en primer lugar, analiza las prescripciones constitucionales relativas a esta materia, tanto de naturaleza material, como es la cláusula del Estado Social o los principios rectores de la política social y económica, como formales, esto es, los relativos al reparto de las competencias en materia de servicios sociales entre la Administración General del Estado y las Comunidades Autónomas. Acertadamente, aunque la regulación de esta cuestión no se encuentra en el texto constitucional, en este punto, la autora explica cuáles son las competencias que las Administraciones Locales tienen en materia de servicios sociales, esto es, delimita el espacio que tanto el legislador básico de régimen local, como los legisladores sectoriales autonómicos le confieren en este ámbito. Tras la reconstrucción del marco constitucional, la autora desentraña la complicada maraña de normas autonómicas en materia de servicios sociales. Para ello, partirá de un análisis de la evolución histórica de esta normativa, agrupándola en diferentes generaciones. Una vez hecho esto, explica cuáles son las características comunes de cada generación de normas, y, finalmente, cuál es la regulación positiva que para los servicios sociales ofrece la ultima y tercera generación de estas disposiciones autonómicas. 
En el cuarto capítulo, la profesora Garrido Juncal estudia la figura del concierto social. En primer lugar, para enmarcar este análisis, describe la relación entre el concierto social y las normas de contratación pública, y ello con fin el de dejar claro que el concierto social es una institución diferente del contrato público. En segundo lugar, la autora analiza las normas reguladoras de los conciertos sociales, poniendo el acento en las limitaciones que experimentan los legisladores autonómicos para desarrollar esta figura de modo íntegro sin invadir las competencias estatales en materia de contratación de las Administraciones Públicas. A continuación, lleva a cabo un exhaustivo análisis de los elementos que estructuran el concierto, tanto objetivos, subjetivos, como formales y procedimentales.

Así las cosas, la valoración global de la presente obra requiere la realización de dos consideraciones diferentes. Una sobre la oportunidad de esta y otra acerca del valor de las aportaciones contenidas en ella. Por lo que se refiere al primer aspecto, no cabe duda de la oportunidad de un trabajo como el presente. Apenas habiendo salido de la Gran Recesión iniciada en 2008, nos hallamos inmersos en la crisis económica que está provocando la pandemia mundial. En este contexto, es evidente la importancia que desempeña el sistema de servicios sociales para garantizar una existencia digna a todos los habitantes de nuestro país. Y, por ende, lo fundamentales que son los estudios rigurosos, como el presente, que contribuyan a clarificar la normativa vigente y a construir dogmáticamente las instituciones esenciales de este sector del ordenamiento jurídico, para permitir la mejora y evolución de la legislación sobre esta materia y, en consecuencia, para posibilitar la mejor respuesta de los poderes públicos a las necesidades sociales. Por lo que respecta a la calidad del contenido de esta monografía, hay que destacar, en primer lugar, su carácter exhaustivo, pues analiza detalladamente el amplio conjunto de normativa autonómica existente en esta materia. En segundo lugar, se debe poner de manifiesto la capacidad de la autora para identificar los problemas que se plantean en este sector, señalando su origen y apuntando las líneas que deberían seguirse para poder dar una adecuada solución a los mismos. Y, en tercer lugar, hay que subrayar la importante sistematización del conjunto normativo que conforma este subsector del Ordenamiento, caracterizado por la existencia de una legislación abundante, confusa y antinómica.

En definitiva, la monografía que acaba de publicar la profesora Andrea Garrido Juncal constituye una obra de gran interés y de muy recomendable lectura, tanto para aquellos que por razones profesionales tienen que enfrentarse día a día con la gestión de los conciertos sociales, como para todos aquellos otros que están interesados en el estudio científico de esta compleja material. 